\title{
Extrapyramidal Side Effects in a Patient with Alcohol Withdrawal Symptoms: A Reflection of Quality of the Mental Health Care System
}

\author{
Mark Mohan Kaggwa (D) \\ Rahel Nkola (D) \\ Sarah Maria Najjuka $\mathbb{D}^{2}$ \\ Felix Bongomin $\mathbb{1}^{3}$ \\ Scholastic Ashaba (D) ${ }^{1}$ \\ Mohammed A Mamun (iD) 4,5 \\ 'Department of Psychiatry, Faculty of \\ Medicine, Mbarara University of Science \\ and Technology, Mbarara, Uganda; \\ ${ }^{2}$ College of Health Sciences, Makerere \\ University, Kampala, Uganda; \\ ${ }^{3}$ Department of Medical Microbiology \\ and Immunology, Faculty of Medicine, \\ Gulu University, Gulu, Uganda; ${ }^{4} \mathrm{CHINTA}$ \\ Research Bangladesh (Centre for Health \\ Innovation, Networking, Training, Action \\ and Research - Bangladesh), Dhaka, \\ Bangladesh; ${ }^{5}$ Department of Public \\ Health and Informatics, Jahangirnagar \\ University, Dhaka, Bangladesh
}

Background: The burden of substance use disorders is increasing in most countries in subSaharan Africa. Individuals with substance use disorders (eg, alcohol use disorder) are at high risk of manifesting extrapyramidal side effects or extrapyramidal symptoms (EPS) during treatment of alcohol-induced mental illness symptoms especially psychosis. EPS management poses a challenge since some of the drugs used for treating EPS have addictive properties. The knowledge about EPS diagnosis and treatment is not well distributed across the health system, with health workers at lower health facilities having least awareness. The present case gives details of a patient who developed EPS during the management of alcohol withdrawal symptoms. Case Details: Following cessation of alcohol use, a 54-year-old man with alcohol use disorder presented with a one-week history of visual, auditory and tactile hallucinations, illusions, insomnia, extreme fear and irritability. He was managed with several daily doses of intramuscular chlorpromazine $100 \mathrm{mg}$, whenever he woke up aggressive from sedation from a peripheral health facility. Four days after his admission, he became mute, stiff, immobile, triple-flexed, tremulous and was drooling saliva. He was referred to a secondary facility for further management while on antipsychotic medication. Finally, he was referred to a tertiary facility, managed with tablets of benzhexol $5 \mathrm{mg}$ twice daily and intravenous diazepam $20 \mathrm{mg}$ per day. Daily follow-up was done using the extrapyramidal symptom rating scale (ESRS) for EPS. EPS symptoms resolved ten days after initiation of treatment.

Conclusion: EPS among individuals with addictive disorders poses a challenge in its management, especially in countries where the mental health care system is not well developed at lowerlevel health facilities. The mental health system has to prepare sustainable interventions to properly manage EPS among the growing population of individuals with addictive disorders through strengthening the mental health policy by training and equipping all health providers with knowledge and skills in managing EPS, increasing finances allocated for mental health and controlling the production and use of addictive substances.

Keywords: extrapyramidal side effects, typical antipsychotics, mental health system, addiction, alcohol use disorder, EPS, withdrawal symptoms, Akandi, Uganda

\section{Introduction}

Extrapyramidal side effects or extrapyramidal symptoms (EPS) are undesired druginduced movement disorders, whose symptoms debilitate, interfering with motor tasks, communication and activities of daily living. ${ }^{1,2}$ The drugs that cause EPS are: (i) dopamine D2 receptor-blocking agents, mainly first-generation antipsychotics, (ii) lithium, (iii) selective serotonin reuptake inhibitors, (iv) tricyclic
Correspondence: Felix Bongomin Department of Medical Microbiology and Immunology, Faculty of Medicine, Gulu University, P.O. Box 166, Gulu, Uganda Email drbongomin@gmail.com 
antidepressants, (v) calcium channel blockers, (vi) stimulants, (vii) antivirals, (viii) antiarrhythmics, (ix) donepezil and (x) valproic acid. ${ }^{1-3}$ The initial manifestation of EPS usually starts within 24 to 48 hours after medication initiation or after a dose increment, as such, and most of the individuals with EPS develop a symptom within 10 days. $^{2}$ The EPS include the symptoms of parkinsonism, akathisia, dystonia, neuroleptic malignant syndrome, tardive dyskinesia and tardive dystonia. ${ }^{1,2}$

The prominent risk factor for EPS is identified in the use of first-generation antipsychotics (FGA), leading to higher prevalence of EPS in low- and middle-income countries (LMICs), as FGA are the mainstay treatment for psychosis. ${ }^{4}$ On the other hand, a noticeable decline in EPS prevalence observed in high-income countries is mainly due to a shift to second-generation antipsychotics (SGA). ${ }^{4}$ Other risk factors include a history of central nervous system damage, alcohol or substance abuse, epilepsy, Parkinson disease, concomitant treatment with other anti-dopaminergic or serotonergic agents, or a history of EPS. ${ }^{1,5,6}$ In consideration of gender-based EPS suffering, diversity is being reported based on the dominant type manifesting. For instance, young male patients on high doses of high-potency antipsychotics are at a higher risk for dystonia, while the risk of parkinsonism and tardive dyskinesia increases among elderly women. ${ }^{2}$ However, diagnosis of EPS can be challenging to differentiate from other idiopathic movement or related disorders (eg, serotonin syndrome, neuroleptic malignant syndrome, chorea and athetosis etc.), if there is no available information of its etiology, treatment and management. ${ }^{2}$

In the context of Uganda, the health system offers services in levels starting with health centers I to IV, then general hospitals, regional referral hospitals (tertiary health facility) and, at the highest level, national referral hospitals. $^{7,8}$ They offer different health services to mental patients, and levels of expertise and knowledge about mental illness increase with the facility level, that is, lower-level centers have no or few mental health experts, although they still have to manage patients with mental illness. ${ }^{7}$ However, Uganda being one of LMICs, people are at higher risk of EPS due to the rampant usage of FGA, but there are no prior case studies that have reported EPSrelated management challenges due to lack of expertise among health workers at lower health facilities. Thus, this paper is the first to present a patient with an alcohol use disorder (addiction from a local herbal drink containing alcohol - not considered addictive on the market) who developed EPS during the management of alcohol withdrawal symptoms, which is anticipated to provide further directions related to EPS diagnosis and management in the LMIC health care setting.

\section{Case Report}

This is a case of a 54-year-old man who was referred to a tertiary health facility, with a five-day history of: (i) generalized body stiffness, (ii) mutism, (iii) urine incontinence, (iv) drooling of saliva, (v) tongue protrusion and (vi) an elevated blood pressure.

Reportedly, he was doing well until three weeks prior to admission into the tertiary health facility (referral hospital) when he presented to a nearby health unit (health center III) with a one-week complaint of seeing things not seen by others, such as snakes and beasts trying to take his life. He was also seeing and feeling insects crawling all over his body, and he was seen on several occasions trying to remove them. With these fears, sleep was disturbed, and he started talking more than usual, especially about the trauma he was going through. When people were not agreeing with what he was telling them, he became angry and was more irritable than usual. Responding to his experiences, he started packing things and telling his wife to shift away to an area without demons and witchcraft from the people of in his village. However, he was taken to church by the family members, where they prayed for him; but this just fueled his irritation, and he turned aggressive and violent towards most of the church members.

With no improvement following the prayers, he was taken to a nearby health center III (HC III). At the HC III, he was commenced on intramuscular (IM) diazepam at a dose of $10 \mathrm{mg}$, and IM chlorpromazine at a dose of $100 \mathrm{mg}$. Instant improvement was observed after the initial doses, but after waking up he continued to be aggressive, and repeat doses of diazepam $10 \mathrm{mg}$ and chlorpromazine $100 \mathrm{mg}$ were added. The doses were repeated every time the patient woke up aggressive or became talkative. After 4 days at the HC III, his wife reported that he suddenly became mute, he could no longer swallow any food and the mouth remained wide open. He became stiff starting with his jaws, then progressively the stiffness involved the neck and later his extremities. Fortunately, his breathing remained normal. But the patient's condition continued to deteriorate, and on the 7th day at a HC III, he was referred to a health center IV, which has a general practitioner doctor, for further investigations and management. 
On arrival at the health center IV (HC IV), he was maintained on the same treatment from the HC III for 2 days as they initiated the investigations for a possible cause of his symptoms. Human immunodeficiency virus antibody and p24 antigen, Treponema pallidum var. pallidum haemagglutination test, complete blood count and malaria tests were performed, and negative results found for these tests. However, that time, he had an elevated blood pressure 193/135 mmHg with a normal body temperature of $37.2{ }^{\circ} \mathrm{C}$. With the suspicion of neuroleptic malignant syndrome, he was immediately referred to a tertiary health facility for further investigations and management by specialist psychiatrists.

At the tertiary health facility, examination revealed a sick middle-aged man with severe body stiffness and lead-pipe rigidity characterized by a triple flexion posturing, inability to stand, mutism, asymmetrical head and neck position, tremors of large amplitude involving the head, and protruding of the tongue. He was sweating profusely, drooling saliva, and appeared dehydrated. $\mathrm{He}$ had a urinary catheter in situ with $150 \mathrm{~mL}$ of urine. Patient had a normal body mass index of $19.3 \mathrm{~kg} / \mathrm{m}^{2}$, mid upper arm circumference of $20.9 \mathrm{~cm}$. He had a tachycardia of 112 beats per minute, tachypnea of 26 breaths per minute, but normal blood pressure of $129 / 79 \mathrm{mmHg}$, oxygen saturation $98 \%$, random blood sugar $3.7 \mathrm{mmol} / \mathrm{L}$, and euthermia $36.5{ }^{\circ} \mathrm{C}$. In addition, he had a Glasgow Coma Scale score of $8 / 15$ (eye opening 4, verbal response 1 , motor response 3 ), normal reflexes, reduced power of all the limbs (3/5). There were no obvious cranial nerve lesions, and he had a negative Kernig's sign but obvious neck rigidity. The rest of the physical examination was normal. The laboratory findings for liver function, renal function, cerebral spinal fluid, urinalysis and blood cultures were not suggestive of a particular etiology. Unfortunately, computed tomographic scan of the brain, serum creatinine phosphatase, urine and blood drug screen, blood level metabolites for antipsychotics were not performed due to their cost and availability in the country.

Based on collateral history from the patient's wife, he neither had any features of anxiety, history of trauma, epilepsy, suicidal ideation, suicide plan or attempt, nor vomited more than usual prior to admission at HC III. But he was reported being a daily alcohol drinker in his early 20 s, and was found drunk most days. To the extent of waking up to a drink every morning, he was unable to perform any normal life activities without drinking.
Fortunately, he stopped the drinking habit when he became a born-again Christian. In the past 20 years, he was reported being a responsible man able to take care of his family as well as performing community duties and responsibilities. After being stable, recently in the past 2 years, the patient started using a local-made herbal energy beverage, "Akandi Juice". The "Akandi Juice" has a hierarchy of energy levels with a commensurate manner of containing higher alcohol concentrations in the higherlevel doses, that is unknown to most of the users (not advertised). He started with the number of 1, then went to number 2 and recently number 3 and 4 . However, after stopping the use of the juice for about 4 days due to several complaints from people about a significant reduction in his functionality similar to when he was drinking over 20 years back, he developed hallucinations and illusions and had the above presentation prior to hospitalization at HC III.

Based on the above presentation, the psychiatry team at the tertiary institution made a diagnosis of EPS with predominantly severe dystonia following management of psychosis due to alcohol withdrawal in a patient with alcohol use disorder based on DSM-V. He was commenced on an anticholinergic agent, benzhexol $5 \mathrm{mg}$ twice daily, daily intravenous (IV) fluid consisting of 1 liter of dextrose 5\% and 1 liter of Ringer's lactate for 3 days. He was also given IV diazepam $20 \mathrm{mg}$ daily for 2 days. The extrapyramidal symptom rating scale (ESRS) ${ }^{9}$ was used to monitor the improvement of the symptoms. As presented in Table 1 , by the 8 th day at the tertiary health facility, he had no more symptoms. On discharge from the tertiary facility, the patient was given counseling about the use of commonly available beverages with unknown components. He was reported doing well with no major effects 3 months after discharge as found in the routine followups.

\section{Discussion}

As in DSM-V, when a person is reported to have compulsive heavy alcohol use and loss of control over alcohol intake, the term alcohol use disorder is used..$^{10}$ Nowadays, the prevalence of alcohol use disorders or alcohol addictions are increasing globally. ${ }^{10,11}$ For instance, a $5.1 \%$ point prevalence was estimated in the year of 2016, which reflects men at 5 times higher risk than the female gender. ${ }^{10,11}$ Moreover, Uganda is documented to have one of the highest levels of alcohol consumption in Africa, with an annual per capita rate of alcohol consumption of 
Table I Extrapyramidal Side Effects (EPS) on Follow-Up of the Patient

\begin{tabular}{|l|l|l|l|l|l|l|l|}
\hline $\begin{array}{l}\text { Follow-Up } \\
\text { Measured Item }\end{array}$ & $\begin{array}{l}\text { Respiratory } \\
\text { Rate }\end{array}$ & $\begin{array}{l}\text { Pulse } \\
\text { Rate }\end{array}$ & $\begin{array}{l}\text { Blood } \\
\text { Pressure }\end{array}$ & Temperature & $\begin{array}{l}\text { Parkinsonism and } \\
\text { Akathisia (max = 102) }\end{array}$ & $\begin{array}{l}\text { Dystonia } \\
(\mathbf{m a x}=\mathbf{6 0})^{\mathbf{a}}\end{array}$ & $\begin{array}{l}\text { Dyskinesia } \\
(\mathbf{m a x}=\mathbf{4 2})^{\mathbf{a}}\end{array}$ \\
\hline Day I & 26 & 112 & $129 / 79$ & 36.5 & 92 & 56 & 3 \\
Day 2 & 24 & 119 & $130 / 80$ & 36.5 & 90 & 55 & 2 \\
Day 3 & 23 & 89 & $125 / 82$ & 36.3 & 88 & 30 & 0 \\
Day 4 & 19 & 93 & $120 / 78$ & 36.0 & 60 & 19 & 12 \\
Day 5 & 18 & 90 & $122 / 76$ & 36.4 & 35 & 9 & 0 \\
Day 6 & 18 & 88 & $120 / 80$ & 36.0 & 12 & 4 & 0 \\
Day 7 & 18 & 80 & $110 / 76$ & 36.5 & 4 & 4 & 0 \\
Day 8 & 16 & 82 & $115 / 73$ & 36.2 & 2 & 1 & 0 \\
\hline
\end{tabular}

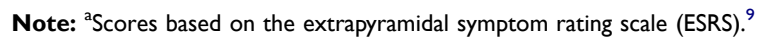

23.7 liters and $5.8 \%$ of the Ugandan population over the age of 15 affected by alcohol use disorder. ${ }^{12,13}$ This is further reinforced by a community survey among 3956 adults in Uganda which indicated that $27 \%$ of the population were heavy alcohol consumers, with $10 \%$ meeting DSM-V criteria for alcohol use disorder. ${ }^{14}$ Excessive use of alcohol is associated with decreased quality of life, leading to severe medical consequences such as liver cirrhosis, cardiomegaly, thiamine deficiency and finally resulting in morbidity and mortality rate increments. ${ }^{10}$ Moreover, individuals who are addicted to alcohol are at risk of mental health challenges, commonly managed with antipsychotic medications, especially FGAs, despite their association with life-threatening EPS. ${ }^{11}$

The present patient was reported to have started using alcohol during his youthful years, as reported by his wife. It is evident that addiction leads to polymorphism of the dopamine receptors D2 (DRD2) that maintains the further risk of addiction later in life (reward effect), despite stopping the risk temporarily. ${ }^{15,16}$ The reduced DRD2 receptors leave the affected individuals with reduced sensitivity for non-habitual rewards except addictive substances such as "Akandi Juice". ${ }^{15,16}$ The consumption of beverages whose contents are not clear yet likely to be harmful like alcohol can lead to direct GABA stimulation, which results in alcohol withdrawal symptoms when their consumption is stopped. The symptoms include visual hallucinations, illusions, extreme fear, psychomotor agitation, irritability and insomnia - consistent with the present case. ${ }^{17,18}$ During the alcohol withdrawal phase, antipsychotics are usually used to control these aforementioned psychotic symptoms. ${ }^{19}$ This dopamine blockade is associated with EPS, but reduces DRD2 occupancies, and puts the addicted individuals at a higher risk of EPS, as evident in the present case. ${ }^{20,21}$ In addition, other case studies have reported EPS in patients with addiction disorders, either induced directly by the substance abuse (amphetamine) or the usage of medications such as antipsychotics, sulpiride and antidepressants during the treatment period. ${ }^{21-24}$ In the present case, the etiology of EPS was the antipsychotic (FGA) medication given in uncontrolled doses. The FGA chlorpromazine is not specific to only dopamine blockage, but also blocks histamine, $\alpha$-adrenergic, and muscarinic receptors which leads to a wide range of EPS presentations as shown in Table $1 .{ }^{25}$ Therefore, the management of individuals with addiction disorder should involve few or no antipsychotics, considering their effects related to EPS. Individuals with addiction have succumbed to mismanagement due to the high levels of stigma towards addiction and several myths about addiction. ${ }^{26,27}$ This has led to addicts being managed with aversion therapy including incarceration and other inhuman methods such as use of high doses of sedatives and antipsychotics, putting them at risk of EPS. ${ }^{28}$

EPS being a life-threatening condition, it is handled as an emergency. In assessment and management of the EPS cases, the "ABCDE approach" is recommended to secure attention on airway, breathing, circulation, disability and exposure. Then, discontinuation of the offending drugs or dose reduction, followed by different treatment modes depending on the EPS symptoms as needed (Table 2). ${ }^{2,29-31}$ However, the management of EPS patients with addiction disorders is likely challenging since most of the medications used to control EPS symptoms have addictive properties - for example, trihexyphenidyl, benzodiazepines, barbiturates and stimulants., ${ }^{4,32-34}$ This increases the risk of reward effect to the newly introduced substance to treat the EPS. Therefore, the health care systems should be ready and designed for such emergency situations with well-trained health care 
Table 2 Management of Extrapyramidal Side Effects (EPS)

\begin{tabular}{|c|c|c|}
\hline Condition & Treatment & Dosage \\
\hline \multirow[t]{3}{*}{ Acute dystonia ${ }^{2,35}$} & Benztropine & $\mathrm{I}-2 \mathrm{mg} \mathrm{IV} / \mathrm{IM} / \mathrm{PO}$ once, then I-2 mg PO I-2 times daily for 7-28 days to prevent recurrence \\
\hline & Diphenhydramine & $\begin{array}{l}25-50 \mathrm{mg} \text { IV/IM/PO once, then } 25 \mathrm{mg} \text { PO every } 4-6 \text { hours or } 50 \mathrm{mg} \text { every } 6-8 \text { hours for } 2-3 \text { days } \\
\text { until symptoms resolve }\end{array}$ \\
\hline & Trihexyphenidyl & 5-15 mg PO divided into 3-4 doses per day. Starting dose $1 \mathrm{mg}$; increase by $2 \mathrm{mg}$ every few days \\
\hline \multirow[t]{5}{*}{ Akathisia $^{2,35}$} & Benztropine & $\begin{array}{l}\mathrm{I}-6 \mathrm{mg} \mathrm{PO} / \mathrm{IM} / \mathrm{IV} \text {. Starting dose } \mathrm{I}-2 \mathrm{mg} 2-3 \text { times daily; increase by } 0.5 \mathrm{mg} \text { every } 5 \text { days to max } \\
\text { dose of } 6 \mathrm{mg} \text {, continue for } \mathrm{I}-2 \text { weeks, then withdraw to reassess treatment need }\end{array}$ \\
\hline & Clonazepam & $0.5-1 \mathrm{mg} P O$ \\
\hline & Diazepam & 5-15 mg PO. Starting dose $2-5 \mathrm{mg}$; titrate up to $15 \mathrm{mg}$ divided into $2-4$ doses per day \\
\hline & Lorazepam & $0.5-2 \mathrm{mg} I \mathrm{~V} / \mathrm{IM} / \mathrm{PO}$ \\
\hline & Mirtazapine & $15 \mathrm{mg} \mathrm{PO}$ \\
\hline \multirow[t]{4}{*}{ Parkinsonism ${ }^{2,35}$} & Amantadine & 100-322 mg PO. Starting dose $129 \mathrm{mg}$ daily; can increase weekly to max of $322 \mathrm{mg}$ \\
\hline & Benztropine & $0.5-6 \mathrm{mg}$ PO/IM/IV. Starting dose 0.5 to I $\mathrm{mg}$ daily; increase by $0.5 \mathrm{mg}$ every 5 days \\
\hline & $\begin{array}{l}\text { Carbidopa/ } \\
\text { levodopa }\end{array}$ & $\begin{array}{l}25-200 \mathrm{mg} \text { carbidopa/ } \mathrm{I00}-2000 \mathrm{mg} \text { levodopa. Tablets available in a } \mathrm{I} / 4 \text { and I/I0 ratio of } \\
\text { carbidopa/levodopa. Starting dose I tablet carbidopa } 25 \mathrm{mg} / \text { levodopa } 100 \mathrm{mg} \text {, increase by I tablet } \\
\text { every I-2 days, and divided into } 3-4 \text { doses per day }\end{array}$ \\
\hline & Trihexyphenidyl & 5-15 mg PO divided into 3-4 doses per day. Starting dose $1 \mathrm{mg}$; increase by $2 \mathrm{mg}$ every few days \\
\hline \multirow[t]{4}{*}{ Tardive dyskinesia $^{35}$} & Deutetrabenazine & $\begin{array}{l}\text { I2-48 mg PO. Starting dose } 12 \mathrm{mg} \text { daily; increase by } 6 \mathrm{mg} \text { per week, to a max dose of } 24 \mathrm{mg} \\
\text { twice daily }\end{array}$ \\
\hline & Reserpine & $0.75-8 \mathrm{mg}$ PO. Starting dose $0.25 \mathrm{mg}$ daily; increase by $0.25 \mathrm{mg}$ per day every few days \\
\hline & Tetrabenazine & 25-200 mg PO. Starting dose $25 \mathrm{mg}$ daily for I week; increase by $25 \mathrm{mg}$ per day every few days \\
\hline & Valbenazine & 40-80 mg PO. Starting dose $40 \mathrm{mg}$ daily; can increase to $80 \mathrm{mg}$ per day after I week \\
\hline \multirow[t]{5}{*}{$\begin{array}{l}\text { Neuroleptic malignant } \\
\text { syndrome }^{29,31,35}\end{array}$} & Bromocriptine & $\begin{array}{l}2.5 \mathrm{mg} \text { PO/via NG tube. Starting dose } 2.5 \mathrm{mg} 2 \text { or } 3 \text { times a day; can increase by } 2.5 \mathrm{mg} \text { every } 24 \\
\text { hours until response. Maximum dose } 45 \mathrm{mg} \text { per day }\end{array}$ \\
\hline & IV dantrolene & $\begin{array}{l}\mathrm{I}-2.5 \mathrm{mg} \text { per } \mathrm{kg} \text {. Start with } \mathrm{I}-2.5 \mathrm{mg} \text { per } \mathrm{kg} \text {; then I } \mathrm{mg} \text { per } \mathrm{kg} \text { every } 6 \text { hours. Maximum dose } \\
\mathrm{I} 0 \mathrm{mg} \text { per } \mathrm{kg} \text { per day }\end{array}$ \\
\hline & Oral dantrolene & 50-200 mg per day \\
\hline & Amantadine & I00-322 mg PO. Starting dose $129 \mathrm{mg}$ daily; can increase weekly to max of $322 \mathrm{mg}$ \\
\hline & $\begin{array}{l}\text { Carbidopa/ } \\
\text { levodopa }\end{array}$ & $\begin{array}{l}\text { 25-200 mg carbidopa/ } / 00-2000 \mathrm{mg} \text { levodopa. Tablets available in a } \mathrm{I} / 4 \text { and I/I0 ratio of } \\
\text { carbidopa/levodopa. Starting dose I tablet carbidopa } 25 \mathrm{mg} / \text { levodopa } 100 \mathrm{mg} \text {, increase by I tablet } \\
\text { every I-2 days, and divided into } 3-4 \text { doses per day }\end{array}$ \\
\hline
\end{tabular}

Note: Data from Pierre, ${ }^{4}$ Dose and Tempel, ${ }^{32}$ Rubinstein ${ }^{33}$ and De La Villarmois et al. ${ }^{34}$

workers at all service levels as prescription of antipsychotics needs proper knowledge about their EPS-related effects. Besides, the caution of addictive drugs is highly suggested being added in the health awareness programs with the motto of "no drug should be used without a physician's recommendation". ${ }^{29}$

In the present case, several risky management options were used, such as the use of higher doses of the FGA chlorpromazine to control the psychotic features in a patient with alcohol use disorder (instead of the preferred SGA), an option available due to the high cost of SGA Uganda. Chlorpromazine was also administered via the IM route, which increases the risk of getting EPS (higher bioavailability of the drug). The management focused more on the psychotic symptoms instead of detoxification of the patient. These risky management approaches 
indicate loopholes in the mental health system. The mental health systems in LMICs like Uganda should adjust and equip health care workers at lower-level health facilities so that they are knowledgeable and ready to handle EPS among individuals with addiction disorders. This challenge can be hindered because of unavailability of enough resources in the health care systems of most LMICs. Thus, of paramount importance is educating health care workers, especially mental health professionals, and making them available to work in the peripheral facilities to enable appropriate diagnosis and treatment of EPS. Besides, this can be best achieved by strengthening the existing mental health policy and other laws governing public health to guide and govern the production of alcohol or other addictive substances contained in beverages like "Akandi Juice".

\section{Conclusions}

The present case described a patient who developed alcohol withdrawal symptoms and was managed with frequent doses of antipsychotics until he developed severe conditions of EPS. It is reported that the EPS conditions were worsened by continued use of antipsychotics despite symptom presence and no appropriate treatment. Based on the present case, it is prudent to say that EPS cases with the presence of addictions pose a challenge in its management. The mental health system in Uganda has to design sustainable interventions to properly manage EPS among the growing population of addicts, especially in rural areas, through strengthening the mental health care system by training more mental health professionals who can be deployed at lower-level health facilities. There is need to allocate more funds to the mental health care system to enable continuous training of primary health care providers about common mental health problems and their management and to create an awareness that EPS are common during treatment of mental health conditions, to improve health outcomes of people who present to these lower-level health facilities for care. Additionally, there should be measures to control the production and use of addictive beverages, whose contents are not clear in most rural settings in Uganda.

\section{Ethical Approval}

Institutional approval was not required for this case publication, but a signed confirmation from the tertiary level head of the psychiatry department was obtained. However, after recovery, the patient provided a written informed consent agreeing to the case being published.

\section{Acknowledgment}

The authors would like to acknowledge their affiliation, the CHINTA Research Bangladesh, which was formerly known as the Undergraduate Research Organization.

\section{Author Contributions}

All authors made substantial contributions to conception and design, acquisition of data, or analysis and interpretation of data; took part in drafting the article or revising it critically for important intellectual content; agreed to submit to the current journal; gave final approval of the version to be published; and agree to be accountable for all aspects of the work.

\section{Funding}

The present study did not get any financial supports. Besides, the authors involved in this research communication do not have any relationships with other people or organizations that could inappropriately influence (bias) the findings.

\section{Disclosure}

The authors reported no conflicts of interest for this work.

\section{References}

1. Abu-Naser D, Gharaibeh S, Al Meslamani AZ, Alefan Q, Abunaser R. Assessment of extrapyramidal symptoms associated with psychotropics pharmacological treatments, and associated risk factors. Clin Pract Epidemiol Mental Health. 2021;17:1. doi:10.2174/ 1745017902117010001

2. D'Souza RS, Hooten WM. Extrapyramidal Symptoms. StatPearls [Internet]; 2020.

3. Li HC, Luo KX, Wang JS, Wang QX. Extrapyramidal side effect of donepezil hydrochloride in an elderly patient: a case report. Medicine. 2020;99(11).

4. Pierre JM. Abuse of psychiatric medications: not just stimulants and benzodiazepines. Curr Psychiatr. 2019;18(1):11.

5. Hedenmalm K, Güzey C, Dahl ML, Yue QY, Spigset O. Risk factors for extrapyramidal symptoms during treatment with selective serotonin reuptake inhibitors, including cytochrome P-450 enzyme, and serotonin and dopamine transporter and receptor polymorphisms. $J$ Clin Psychopharmacol. 2006;26(2):192-197. doi:10.1097/01.jcp.0000203 200.96205.34

6. Dayalu P, Chou KL. Antipsychotic-induced extrapyramidal symptoms and their management. Expert Opin Pharmacother. 2008;9 (9):1451-1462. doi:10.1517/14656566.9.9.1451

7. Kigozi F, Ssebunnya J, Kizza D, Cooper S, Ndyanabangi S. An overview of Uganda's mental health care system: results from an assessment using the world health organization's assessment instrument for mental health systems (WHO-AIMS). Int J Ment Health Syst. 2010;4 (1):1-9. doi:10.1186/1752-4458-4-1

8. Kamwesiga J. Uganda Health Care System. Kampala, Uganda: Makerere University; 2011.

9. Chouinard G, Margolese HC. Manual for the extrapyramidal symptom rating scale (ESRS). Schizophr Res. 2005;76(2-3):247-265. doi:10.1016/j.schres.2005.02.013 
10. Carvalho AF, Heilig M, Perez A, Probst C, Rehm J. Alcohol use disorders. Lancet. 2019;394(10200):781-792. doi:10.1016/S01406736(19)31775-1

11. Rehm J, Shield KD. Global burden of disease and the impact of mental and addictive disorders. Curr Psychiatry Rep. 2019;21 (2):1-7. doi:10.1007/s11920-019-0997-0

12. World Health Organization. Global Status Report on Road Safety 2015. World Health Organization; 2015.

13. Tumwesigye NM, Kasirye R, Nansubuga E. Is social interaction associated with alcohol consumption in Uganda? Drug Alcohol Depend. 2009;103(1-2):9-15. doi:10.1016/j.drugalcdep.2009.01.016

14. Kabwama SN, Ndyanabangi S, Mutungi G, Wesonga R, Bahendeka SK, Guwatudde D. Alcohol use among adults in Uganda: findings from the countrywide non-communicable diseases risk factor cross-sectional survey. Glob Health Action. 2016;9 (1):31302. doi:10.3402/gha.v9.31302

15. Wise RA, Robble MA. Dopamine and addiction. Ann Rev Psychol. 2020;71:79-106. doi:10.1146/annurev-psych-010418-103337

16. Noble EP. Addiction and its reward process through polymorphisms of the D 2 dopamine receptor gene: a review. Eur Psychiatry. 2000;15 (2):79-89. doi:10.1016/S0924-9338(00)00208-X

17. American Psychiatric Association, A. P., \& American Psychiatric Association. Diagnostic and Statistical Manual of Mental Disorders: DSM-5; 2013.

18. Farrokh S, Roels C, Owusu KA, Nelson SE, Cook AM. Alcohol withdrawal syndrome in neurocritical care unit: assessment and treatment challenges. Neurocrit Care. 2020:1-15.

19. Stankewicz HA, Richards JR, Salen P. Alcohol Related Psychosis. StatPearls [Internet]; 2020.

20. Kapur S, Zipursky R, Jones C, Remington G, Houle S. Relationship between dopamine D2 occupancy, clinical response, and side effects: a double-blind PET study of first-episode schizophrenia. Am J Psychiatry. 2000;157(4):514-520. doi:10.1176/appi.ajp.157.4.514

21. Potvin S, Blanchet P, Stip E. Substance abuse is associated with increased extrapyramidal symptoms in schizophrenia: a meta-analysis. Schizophr Res. 2009;113(2-3):181-188. doi:10.1016/ j.schres.2009.06.010

22. De Maio D, Caponeri MA, Cicchetti V, Mellado C, Scieghi G. Sulpiride and extrapyramidal syndromes in chronic heroin addiction. Neuropsychobiology. 1978;4(1):36-39. doi:10.1159/ 000117618

23. Lundh H, Tunving K. An extrapyramidal choreiform syndrome caused by amphetamine addiction. J Neurol Neurosurg Psychiatry. 1981;44(8):728-730. doi:10.1136/jnnp.44.8.728
24. Temmingh HS, van den Brink W, Howells F, Sibeko G, Stein DJ. Methamphetamine use and antipsychotic-related extrapyramidal side-effects in patients with psychotic disorders. J Dual Diagn. 2020;16(2):208-217. doi:10.1080/15504263.2020.1714099

25. Mann SK, Marwaha R. Chlorpromazine. StatPearls; 2019.

26. Griffiths MD, Demetrovics Z, Atroszko PA. Ten myths about work addiction. $J$ Behav Addict. 2018;7(4):845-857. doi:10.1556/ 2006.7.2018.05

27. Kaggwa MM. Simplifying Addiction. Subst Abuse Rehabil. 2021; Volume 12:23-26. doi:10.2147/SAR.S307387

28. Inanambrastate $\mathrm{T}$. The effect of aversion therapy on students'attitude. GSJ. 2019;7(9).

29. Kiyingi M, Bongomin F, Kizito M, Kaddumukasa M. Neuroleptic malignant syndrome: early diagnosis saves lives in low-resource settings. Int Med Case Rep J. 2020;13:359. doi:10.2147/IMCRJ. S270332

30. Caffrey D, Sowden GL. A missed case of lurasidone induced laryngospasm: a case study and overview of extrapyramidal symptom identification and treatment. Int $J$ Psychiatry Med. 2020;0091217420943786. doi:10.1177/0091217420943786

31. Berman BD. Neuroleptic malignant syndrome: a review for neurohospitalists. Neurohospitalist. 2011;1(1):41-47. doi:10.1177/ 1941875210386491

32. Dose M, Tempel HD. Abuse potential of anticholinergics. Pharmacopsychiatry. 2000;33(Sup.1):43-46. doi:10.1055/s-20007583

33. Rubinstein JS. Abuse of antiparkinsonism drugs: feigning of extrapyramidal symptoms to obtain trihexyphenidyl. JAMA. 1978;239 (22):2365-2366. doi:10.1001/jama.239.22.2365

34. De La Villarmois EA, Constantin MF, Pérez MF. From benzodiazepine prescription to dependence: learning processes Involved. In: Gargiulo PÁ, Mesones Arroyo HL, editors. Psychiatry and Neuroscience Update. Cham: Springer; 2021:213-236.

35. Pringsheim T, Doja A, Belanger S, Patten S; Canadian Alliance for Monitoring Effectiveness and Safety of Antipsychotics in Children (CAMESA) guideline group. Treatment recommendations for extrapyramidal side effects associated with second-generation antipsychotic use in children and youth. Paediatr Child Health. 2011;16 (9):590-598. doi:10.1093/pch/16.9.590
Risk Management and Healthcare Policy

\section{Publish your work in this journal}

Risk Management and Healthcare Policy is an international, peerreviewed, open access journal focusing on all aspects of public health, policy, and preventative measures to promote good health and improve morbidity and mortality in the population. The journal welcomes submitted papers covering original research, basic science, clinical \& epidemiological studies, reviews and evaluations, guidelines, expert opinion and commentary, case reports and extended reports. The manuscript management system is completely online and includes a very quick and fair peer-review system, which is all easy to use. Visit http://www.dovepress.com/testimonials.php to read real quotes from published authors. 